\title{
Understanding disease and illness
}

\author{
Jeremy R. Simon' ${ }^{1}$ Havi Carel $^{2} \cdot$ Alexander Bird $^{2}$
}

Published online: 13 July 2017

(C) Springer Science+Business Media B.V. 2017

We are pleased and greatly honored to present to the readers of Theoretical Medicine and Bioethics a selection of the wonderful papers presented at the 6th Philosophy of Medicine Roundtable, held in Bristol in August 2015. As at the prior Roundtables, held in Birmingham (Alabama), Rotterdam, San Sebastian, and New York, a wide variety of papers from around the world were presented, including a keynote presentation by Rachel Cooper of Lancaster University. As always, in keeping with the Roundtable name and mission, the conference focused on philosophical aspects of medicine beyond bioethics, thus providing the only regular gathering devoted to this large and growing field of philosophy.

And it is indeed growing. In the two years since papers from the last Roundtable appeared in this journal, there have been no fewer than nine books published in the field, with volumes written by Havi Carel [1], Benjamin Smart [2], and Mark Sullivan [3], collections edited by Robyn Bluhm [4], Giovanni Boniolo and Virginia Sanchini [5], Boniolo and Marco Nathan [6], and Elodie Giroux [7], and textbooks edited by Miriam Solomon, Jeremy Simon, and Harold Kincaid [8], James Marcum [9], and Thomas Schramme and Steven Edwards [10]. The recent release of three textbooks almost simultaneously (all parts of larger series) following on only one previously [11] is especially significant. It speaks to a growing recognition of philosophy of medicine as an essential part of philosophy more generally as well as, one hopes, to a growing demand for texts at the student level.

The papers presented at the conference included, not for the first time, several focused on psychiatric conditions and practice, including Prof. Cooper's keynote. This is notable because the Roundtable was originally conceived, at least in part, as a complement to already existing forums for philosophy of psychiatry. However, these

Jeremy R. Simon

js1115@columbia.edu

1 Columbia University, 622 W. 168th, VC 2-260, New York, NY 10032, USA

2 University of Bristol, Cotham House, Cotham Hill, Bristol BS6 6JL, UK 
papers, some included here, represent an acknowledgement that while philosophy of psychiatry has some concerns-especially those relating to aspects of mind and mental experience-that remain its own, on many matters, the concerns of philosophy of medicine and philosophy of psychiatry are unsurprisingly the same.

As noted above, this issue contains only a selection of the papers presented at the Roundtable. Some of the remainder have already appeared or will soon appear in Studies in History and Philosophy of Biological and Biomedical Sciences [12], this journal [13], Perspectives in Biology and Medicine [14], Journal of Medicine and Philosophy [15], and Mind [16]. We trust that many of the other presented papers will find their way to print in the near future as well. We should also note that in contrast with prior selections, this issue contains one paper not presented at the roundtable. Jonathan Sholl's presentation was already committed to another journal. However, he offered us instead an alternative paper that is included in this issue.

The issue opens with two papers focusing on the concept of disease. In the eyes of many, the refutation of the biostatistical account of Christopher Boorse has shown the naturalistic approach to understanding the concept of disease to be unworkable. But, one might respond, even if Boorse's view does have problems in detail, the fundamental idea that disease is a matter of a failure of function, found also in Jerome Wakefield's account, is sound. Benjamin Chin-Yee and Ross Upshur, in "Re-evaluating Concepts of Biological Function in Clinical Medicine: Towards a New Naturalistic Theory of Disease" [17], look carefully at debates in the philosophy of biology literature concerning the concept of biological function. They draw on Denis Walsh's "Situated Darwinism" in their account of dysfunction. They note that the resulting view, while naturalistic, also accommodates important aspects of normative and phenomenological approaches insofar as elements of the latter are found in Situated Darwinism's approach to biological function. This allows for a conception of disease that is rooted in biology and also has clinical advantages.

An understanding of the concept of disease may be thought to be important because it is central to appreciating the limits of medicine. And the latter is important because of a frequently expressed concern that too many aspects of human life have been medicalized. Jonathan Sholl, in "The Muddle of Medicalization: Pathologizing or Medicalizing?" [18], shows that the equation between medicalizing and pathologizing is too simplistic. He does so through a careful examination of the relationship between these two concepts. It is clear, he shows, that there is medicalization without pathologizing-many examples including treatment for baldness and medical attention during pregnancy demonstrate this. Preventive medicine, in particular, shows how we can accept and indeed welcome medical intervention without pathologizing those intervened upon. Sholl notes that the reverse, the possibility of pathologizing without medicalizing, is less apparent but real nonetheless. Therapeutic nihilism is the view that while there are diseases, attempts to cure them do more harm than good and should not be undertaken. While a less plausible position these days than it once was, therapeutic nihilism is nonetheless a coherent view. And, in particular cases, one might well think that while one can still recognize illness, de-medicalization might have much to be said for it-whether that is accepting a cold or mild flu without demanding (useless) 
antibiotics or accepting that in terminal conditions, allowing nature to take its course may well be preferable to the harm done by medical intervention. Furthermore the benefits of pathologizing - having one's condition recognized as a disease-are not limited to the medicalization this might bring about (which include, e.g., changing others' perceptions of the individual, relieving guilt, etc.). Paying attention to the distinction between pathologizing and medicalizing allows for a more nuanced and accurate assessment of the harms and benefits of each.

The next two papers discuss issues arising from consideration of psychiatry. In "Symptom Modelling can be Influenced by Psychiatric Categories: Choices for Research Domain Criteria (RDoC)" [19], Sam Fellowes argues that psychiatric researchers typically consider the modelling of psychiatric symptoms to be free from psychiatric categories. Thus, the RDoC approach takes inadequacies of existing psychiatric categories as holding back causal investigation. This approach aims to circumvent existing psychiatric categories by directly investigating the causal basis of symptoms. This methodological approach exploits the supposed lack of influence of psychiatric categories on symptom modelling, taking psychiatric symptoms as the same regardless of which psychiatric category is employed or if no psychiatric category is employed. As Fellowes points out, this assumption is not always true. He shows how psychiatric categories can influence symptom modelling. For example, identical behavior may be seen to express different symptoms, based on an individual's psychiatric diagnosis. Fellowes discusses four ways RDoC could address this issue: by assigning symptoms based upon the most relevant cause, limiting how many different types of symptoms are employed, seeing symptoms as less mutually exclusive, and accepting that psychiatric categories can legitimately influence symptom modelling.

In "Where's the Problem? Considering Laing and Esterson's Account of Schizophrenia, Social Models of Disability, and Extended Mental Disorder" [20], Rachel Cooper compares R.D. Laing and A. Esterson's account of schizophrenia, social models of disability, and accounts of extended mental disorder. These accounts claim that some putative disorders should not be thought of as reflecting biological or psychological dysfunction within the afflicted individual, but are instead external problems to be located in the family or in the material and social environment. Cooper argues that problems should not be located within an individual putative patient in cases where there is some acceptable test environment in which there is no problem. She claims, however, that Laing and Esterson's argument that schizophrenia is not something within diagnosed patients fails because they do not show that the diagnosed women in their study function adequately in any environment.

The third pair of papers discusses what might be described as philosophical questions raised by the patient's perspective. A central component of the autonomy highly valued by contemporary medical ethics is information. So it makes sense to give patients maximum information about their condition. But is such information an unalloyed good? Mary Jean Walker and Wendy Rogers, in "Diagnosis, Narrative Identity, and Asymptomatic Disease" [21], argue that it is not. They show that diagnosis in cases of asymptomatic diseases can be potentially harmful to patients. While a patient who suffers symptoms and seeks an explanation from a doctor is to 
some degree prepared for bad news, a patient who has suffered from no symptoms may find the diagnosis of disease both unexpected and particularly disruptive. Walker and Rogers relate the disruption and its effects to the thesis that people attempt to integrate their experiences and other facts about themselves into a coherent narrative regarding their lives. Asymptomatic disease presents difficulties for straightforward integration. In particular, there is a mismatch between the patient's past experience, which is of good health, and the information that they are suffering from a disease. This mismatch can lead patients to conclude that they are the sort of person whose feelings and sensations are not reliable indicators of health status, thereby leading to feelings of vulnerability. Or they may even resolve the mismatch by unconsciously causing themselves to experience symptoms of the disease or by reinterpreting other feelings (e.g., the effects of treatment) as symptoms. Walker and Rogers carefully articulate the ways that such attempts to manage one's narrative can lead to various harms, such as false beliefs and the negative feelings they give rise to. Given that the routes by which patients might come to be given a diagnosis of asymptomatic disease (whether correctly or incorrectly) are increasing (e.g., screening programs, more sophisticated and sensitive tests), it is important to be aware of the harms such diagnoses might cause and to take them into consideration in weighing the benefits of such technologies.

In "Exemplars, Ethics, and Illness Narratives" [22], Ian James Kidd discusses how the moral value of illness narratives should be understood. Kidd suggests that reading first-person narratives of the experience of illness can be morally instructive or educative. But although they are ubiquitous and typically sincere, the precise nature of such educative experiences is puzzling. Such narratives typically lack the features that modern philosophers regard as constitutive of moral reason, namely, assuming or establishing some set of moral facts or principles, then inferring from them through some specified rational procedure a set of prescriptions for conduct. Kidd argues that such puzzlement should disappear, and the morally educative power of illness narratives explained, if one distinguishes two different styles of moral reasoning: an inferentialist style that generates the puzzlement and an alternative exemplarist style that offers a compelling explanation of the morally educative power of pathographic literature. The exemplarist style of moral reasoning emphasizes individual behavior, the importance of role models, and the uniqueness of one's moral responses to adversity as significant factors underpinning and justifying an exemplarist approach to moral reasoning. These explain why illness narratives can be morally educative without containing moral argumentation.

Finally, Andrew Turner uses the UK House of Commons's report on homeopathy to investigate the place of "implausibility arguments" in evidence-based medicine [23]. In 2009, the House of Commons produced a report on the evidence for homeopathy. Unsurprisingly, they did not feel the evidence supported it. However, surprisingly, at least to Turner, they minimized the value of arguments from the apparent implausibility of the proposed mechanism for homeopathic treatments. Turner argues that this undervaluing is unfortunate in that such arguments would have made their conclusion stronger. He notes that the minimizing arises from a misunderstanding of the place and value of mechanistic evidence in evidence-based medicine. A proper understanding of its place, he argues, is essential in evaluating the evidence not just for homeopathy but for many other therapies as well. 
We hope that you, the reader, enjoy these papers, keep an eye out for papers from the 2017 Roundtable in Toronto, and consider joining us in Paris in 2019.

Acknowledgements The 5th Philosophy of Medicine Roundtable hosted in Bristol in 2015 and the editorial work of Prof. Havi Carel were generously supported by a Senior Investigator Award from the Wellcome Trust titled "The Life of Breath" (Grant Number 103340) (see www.lifeofbreath.org). The authors would also like to thank the other members of the scientific committee for the Roundtable: Rachel Ankeny, Alex Broadbent, Fred Gifford, Harold Kincaid, Miriam Solomon, Julian Reiss, and David Teira.

\section{References}

1. Carel, Havi. 2016. Phenomenology of illness. Oxford: Oxford University Press.

2. Smart, Benjamin. 2016. Concepts and causes in the philosophy of disease. Basingstoke: Palgrave MacMillan.

3. Sullivan, Mark. 2016. The patient as agent of health and health care. Oxford: Oxford University Press.

4. Bluhm, Robyn (ed.). 2016. Knowing and acting in medicine. London: Rowman \& Littlefield International.

5. Boniolo, Giovanni, and Virginia Sanchini (eds.). 2016. Ethical counselling and medical decisionmaking in the era of personalized medicine. Heidelberg: Springer.

6. Boniolo, Giovanni, and Marco J. Nathan (eds.). 2017. Philosophy of molecular medicine: Foundational issues in research and practice. New York: Routledge.

7. Giroux, Elodie (ed.). 2016. Naturalism in the philosophy of health: Issues and implications. Switzerland: Springer.

8. Solomon, Miriam, Jeremy R. Simon, and Harold Kincaid (eds.). 2016. The Routledge companion to philosophy of medicine. New York: Routledge.

9. Marcum, James (ed.). 2016. The Bloomsbury companion to contemporary philosophy of medicine. London: Bloomsbury.

10. Schramme, Thomas, and Steven Edwards (eds.). 2017. Handbook of the philosophy of medicine. Dordrecht: Springer.

11. Gifford, Fred (ed.). 2011. Philosophy of medicine. Amsterdam: North Holland.

12. González-Moreno, Maria, Cristian Saborido, and David Teira. 2015. Disease-mongering through clinical trials. Studies in History and Philosophy of Biological and Biomedical Sciences 51: 11-18.

13. Sholl, Jonathan. 2015. Putting phenomenology in its place: Some limits of a phenomenology of medicine. Theoretical Medicine and Bioethics 36: 391-410.

14. Sholl, Jonathan. 2016. Escaping the conceptual analysis straightjacket: Pathological mechanisms and Canguilhem's biological philosophy. Perspectives in Biology and Medicine 58: 395-418.

15. Bluhm, Robyn, and Borgerson, Kirstin. Forthcoming. An epistemic argument for research-practice integration in medicine. Journal of Medicine and Philosophy.

16. Kingma, Elselijn M. Forthcoming. Were you a part of your mother?: The metaphysics of pregnancy. Mind.

17. Chin-Yee, Benjamin, and Ross E.G. Upshur. 2017. Re-evaluating concepts of biological function in clinical medicine: Towards a new naturalistic theory of disease. Theoretical Medicine and Bioethics. doi:10.1007/s11017-017-9410-3.

18. Sholl, Jonathan. 2017. The muddle of medicalization: Pathologizing or medicalizing? Theoretical Medicine and Bioethics. doi:10.1007/s11017-017-9414-z.

19. Fellowes, Sam. 2017. Symptom modelling can be influenced by psychiatric categories: Choices for research domain criteria (RDoC). Theoretical Medicine and Bioethics. doi:10.1007/s11017-0179416-x.

20. Cooper, Rachel. 2017. Where's the problem? Considering Laing and Esterson's account of schizophrenia, social models of disability, and extended mental disorder. Theoretical Medicine and Bioethics. doi:10.1007/s11017-017-9413-0.

21. Walker, Mary Jean, and Wendy A. Rogers. 2017. Diagnosis, narrative identity, and asymptomatic disease. Theoretical Medicine and Bioethics. doi:10.1007/s11017-017-9412-1. 
22. Kidd, Ian James. 2017. Exemplars, ethics, and illness narratives. Theoretical Medicine and Bioethics. doi:10.1007/s11017-017-9411-2.

23. Turner, Andrew. 2017. Evaluating the UK House of Commons Science and Technology Committee's position on the implausible effectiveness of homeopathic treatments. Theoretical Medicine and Bioethics. doi:10.1007/s11017-017-9415-y. 